\title{
CHANGING AUTOMOTIVE BODY MEASUREMENT SYSTEM PARADIGMS WITH 3D NON-CONTACT MEASUREMENT SYSTEMS
}

\author{
A Comparison of CMM vs. CogniTens Optigo 3D Non-Contact System
}

\section{UMTRI Technical Report: UMTRI-2003-43}

Patrick C. Hammett, Ph.D., Kenneth D. Frescoln and Luis Garcia-Guzman, Ph.D. Office for the Study of Automotive Transportation (OSAT) University of Michigan Transportation Research Institute (UMTRI) The University of Michigan 2901 Baxter Road Ann Arbor, Michigan 48109-2150

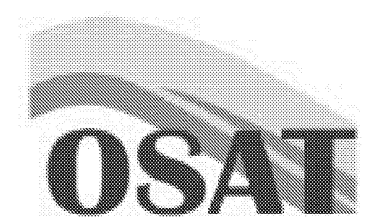

University of Michigan

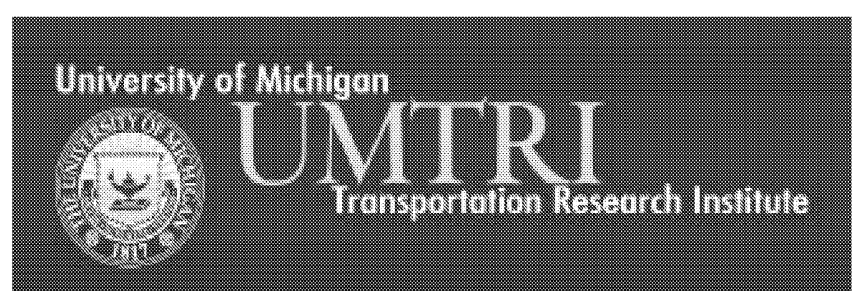

December 5, 2003 
Technical Report Documentation Page

\begin{tabular}{|c|c|c|c|}
\hline \multicolumn{2}{|l|}{$\begin{array}{l}\text { 1. Report No. } \\
\text { UMTRI-2003-43 }\end{array}$} & \multicolumn{2}{|c|}{ 3. Recipient's Catalog No. } \\
\hline \multirow{2}{*}{\multicolumn{2}{|c|}{$\begin{array}{l}\text { 4. Title and Subtitle } \\
\text { Changing Automotive Body Measurement System Paradigms with } \\
\text { 3D Non-Contact Measurement Systems }\end{array}$}} & \multicolumn{2}{|c|}{$\begin{array}{l}\text { 5. Report Date } \\
\text { December } 2003\end{array}$} \\
\hline & & \multicolumn{2}{|c|}{$\begin{array}{l}\text { 6. Performing Organization Code } \\
379078\end{array}$} \\
\hline \multicolumn{2}{|c|}{$\begin{array}{l}\text { 7. Author(s) } \\
\text { Hammett, P.C., Frescoln, K.D., and Garcia-Guzman, L. }\end{array}$} & \multicolumn{2}{|c|}{$\begin{array}{l}\text { 8. Performing Organization Report No. } \\
\text { UMTRI-2003-43 }\end{array}$} \\
\hline \multirow{2}{*}{\multicolumn{2}{|c|}{$\begin{array}{l}\text { 9. Performing Organization Name and Address } \\
\text { The University of Michigan } \\
\text { Transportation Research Institute } \\
\text { 2901 Baxter Road } \\
\text { Ann Arbor, Michigan 48109-2150 U.S.A. }\end{array}$}} & \multicolumn{2}{|c|}{ 10. Work Unit no. (TRAIS) } \\
\hline & & \multicolumn{2}{|c|}{$\begin{array}{l}\text { 11. Contract or Grant No. } \\
\text { N002690 }\end{array}$} \\
\hline \multirow{2}{*}{\multicolumn{2}{|c|}{$\begin{array}{l}\text { 12. Sponsoring Agency Name and Address } \\
\text { General Motors - NAO Small Car } \\
\text { 1420 Stephenson Hwy. } \\
\text { P.O. Box } 7025 \\
\text { MC: } 480-991-320 \\
\text { Troy, MI } 48083\end{array}$}} & \multicolumn{2}{|c|}{ 13. Type of Report and Period Covered } \\
\hline & & \multicolumn{2}{|c|}{ 14. Sponsoring Agency Code } \\
\hline \multicolumn{4}{|l|}{ 15. Supplementary Notes } \\
\hline \multicolumn{4}{|c|}{ 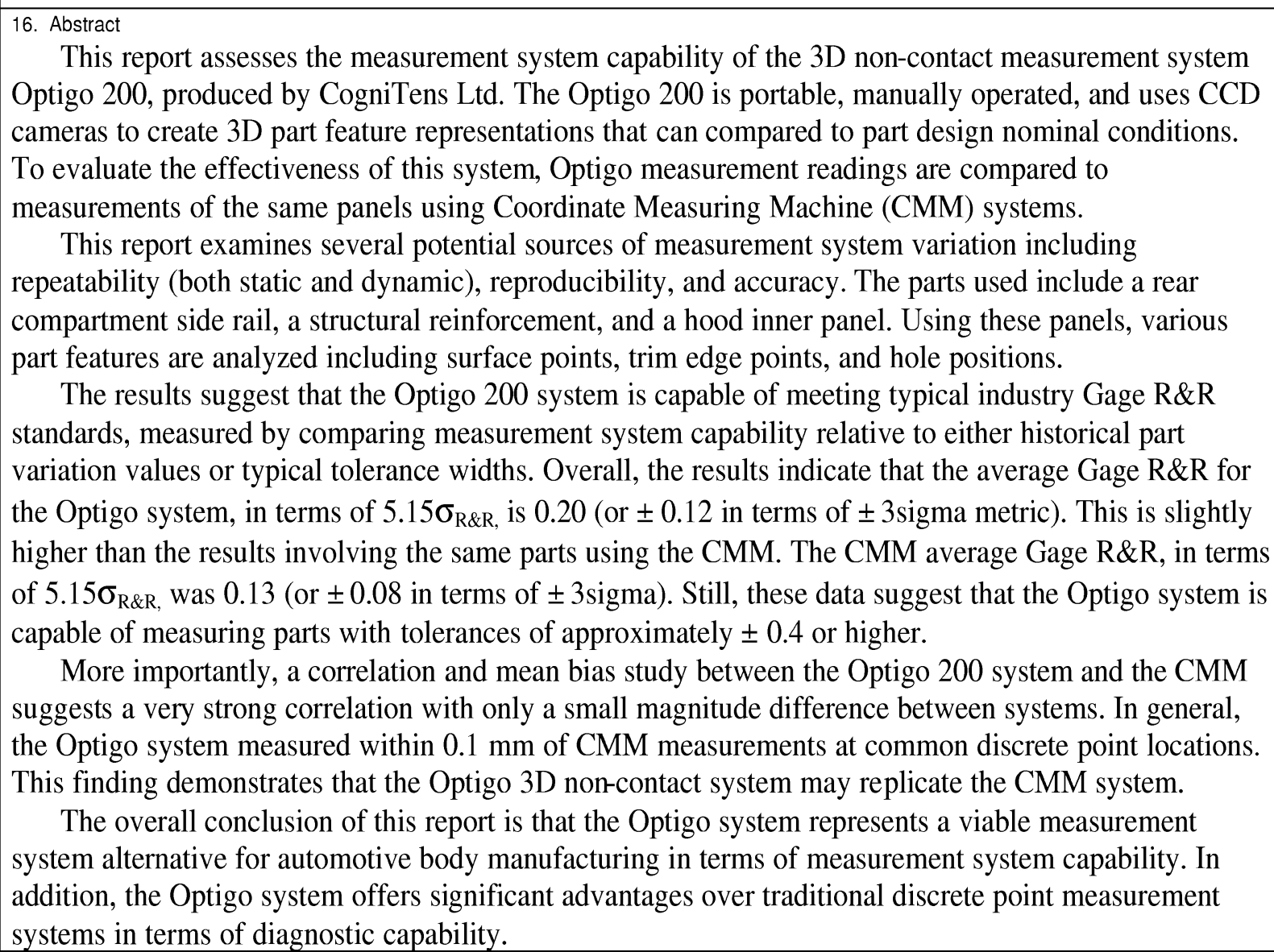 } \\
\hline \multicolumn{3}{|c|}{$\begin{array}{l}\text { 17. Key Words } \\
\text { measurement system capability, 3D non-contact measurement system, CMM, } \\
\text { Optigo, sheet metal stamping, automotive body, Gage R\&R }\end{array}$} & \\
\hline $\begin{array}{l}\text { 19. Secu } \\
\text { None }\end{array}$ & $\begin{array}{l}\text { 20. Secu } \\
\text { None }\end{array}$ & $\begin{array}{l}\text { D. of } \mathrm{Pac} \\
28\end{array}$ & 22. Price \\
\hline
\end{tabular}




\section{$\underline{\text { Table of Contents }}$}

List of Figures and Tables

iv

Executive Summary

$\mathbf{v}$

1. Introduction

2. 3D Non-Contact Measurement and the CogniTens System

3. Potential Sources of Measurement Variation

4. Measurement System Analysis Case Studies

4.1 Mapping Process Measurement Error and Static Repeatability 12

4.2 Gage Repeatability and Reproducibility Analysis 15

4.3 Optigo Vs. CMM: Feature Correlation and Accuracy

5. Conclusions

References 


\section{$\underline{\text { List of Figures and Tables }}$}

\section{Figures}

Figure 1. Sample Checking Fixture with Discrete Point Measurement Location 1

Figure 2. Sample Output from a CogniTens Optigo 200 System 3

Figure 3. Measuring a Stamping Rail Panel Using Targets 5

Figure 4. Measurement Results Relative to CAD Design Nominals 6

Figure 5. Hood Inner Panel Measurement Results with Discrete Points 7

$\begin{array}{lr}\text { Figure 6. Accuracy, Repeatability, and Reproducibility } & 8\end{array}$

Figure 7. Global Body Coordinate System (Front, Center, Bottom: 0,0,0) 10

$\begin{array}{ll}\text { Figure 8. Part Feature Types } & 11\end{array}$

Figure 9. Rail Study: Mapping Effect and Static Repeatability 12

$\begin{array}{lr}\text { Figure 10. Rail Measurements } & 13\end{array}$

Figure 11. Structural Reinforcement Panel with Discrete Point Dimensions 16

Figure 12. Correlation Differences for Each Set of Panel Measurement by Type 21

Figure 13. Mean Differences for Each Set of Panel Measurement by Feature Type 21

Tables

Table 1. Fixture Mapping Effect $\quad 13$

Table 2. Static Repeatability Error (Note: Average CMM $\sigma_{\text {static }} \sim$ 0.007) 14

Table 3. Static Repeatability Error by Feature Type (Rail Part) 15

Table 4. Full Gage R\&R Comparison: CMM vs. Optigo 16

Table 5. Gage R\&R Relative to Historical Variation and Tolerances 17

Table 6. Gage R\&R Relative to Observed Study Variation 18

Table 7. Theoretical Tolerances and Measurable Inherent Part Variation 19

Table 8. Reinforcement Panel Correlation/ Mean Bias Measurement Differences 20 


\section{Executive Summary}

The purpose of this report is to assess the measurement system capability of a 3D noncontact measurement system. Three-dimensional non-contact systems generate thousands of measurements or a cloud of points. For complex-shaped parts, point cloud data provides a means to fully characterize a part shape, as opposed to only measuring at discrete point locations. A main driver for 3D non-contact measurement point cloud data is that it provides an enhanced problem solving diagnostic capability for lower total measurement system costs.

The non-contact system used for this study is the Optigo 200 produced by CogniTens, Ltd. This system is a portable, manually operated non-contact measurement system that uses $\mathrm{CCD}$ cameras to create $3 \mathrm{D}$ part feature representations that may be compared to part design nominal conditions. To evaluate the effectiveness of this system, Optigo 200 measurement readings were compared to measurements of the same panels using Coordinate Measuring Machine (CMM) systems.

This report examines several potential sources of measurement system variation including repeatability (both static and dynamic), reproducibility, and accuracy. Accuracy measurements are based on comparing Optigo 200 data to CMM measurements for identical automotive stamped parts. The parts used in the case study include a rear compartment side rail, a structural reinforcement, and a hood inner panel. Using these panels, various part features are analyzed including surface points, trim edge points, and hole positions.

The results of these studies suggest that the Optigo 200 is capable of meeting typical industry Gage R\&R standards, measured by comparing measurement system capability relative either to historical part variation values or to typical tolerance widths. Overall, the results of the case studies indicate that the average Gage $R \& R$ for the Optigo system, in terms of $5.15 \sigma_{R} \&$, is 0.20 (or \pm 0.12 in terms of \pm 3 sigma metric). This is slightly higher than the results involving the same parts using the CMM. The CMM average Gage R\&R, in terms of $5.15 \sigma_{R \& R}$, was 0.13 (or \pm 0.08 in terms of \pm 3 sigma). Still, these data suggest that the Optigo 200 is capable of measuring parts with tolerances of approximately \pm 0.4 or higher. (Note: Typical surface and trim edge tolerances for sheet metal parts are $\pm 0.5 \mathrm{~mm}$ or higher.)

More importantly, a correlation and mean bias study between the Optigo 200 system and the CMM suggest a very strong correlation with only a small magnitude difference between 
systems. In general, the Optigo system measured within $0.1 \mathrm{~mm}$ of CMM measurements at common discrete point locations. This finding demonstrates that the Optigo 200 3D non-contact system may replicate the CMM system.

Although the Optigo system is shown capable of meeting typical industry measurement capability standards, some potential challenges exist. For example, the static repeatability of the Optigo system was not as high as that achieved by the CMM. One explanation is that the CMM uses a physical touch probe moving along an ijk vector path normal to the part surface. This appears to allow for better static repeatability than does the 3D non-contact system, which must virtually calculate the normal-to-surface measurements at discrete point locations. In addition, some small differences between systems may exist due to the location at which a feature is measured. In the case of trim edge points, the Optigo system measures along the top surface of the part whereas a CMM may measure in the middle of the blank. Overall, these differences are considered relatively minor.

The overall conclusion of this study is that the Optigo 200 system represents a viable measurement system alternative for automotive body manufacturing in terms of measurement system capability. In addition, the Optigo system offers significant advantages over traditional discrete point measurement systems in terms of diagnostic capability. The system provides the ability to fully measure a panel shape and thus the potential to make better decisions on how best to resolve downstream process dimensional concerns. 


\section{Introduction}

Part measurement systems used in automotive body applications largely consist of discrete point inspection. Here, a manufacturer takes a stamped or welded assembly part and identifies key features at specific discrete locations defined by three-dimensional coordinates (X,Y, and Z). Manufacturers then measure these discrete locations relative to part design nominal dimensions. These discrete measurements are typically made using either Coordinate Measuring Machines (CMM) or traditional checking fixtures with electronic data collection bushings and measurement probes (see Figure 1). This approach closely links the cost of checking (e.g., time and resources to measure at a specific location) with the number of discrete points identified. As a result, automotive body manufacturers often seek to minimize the number of discrete inspection points to reduce costs.

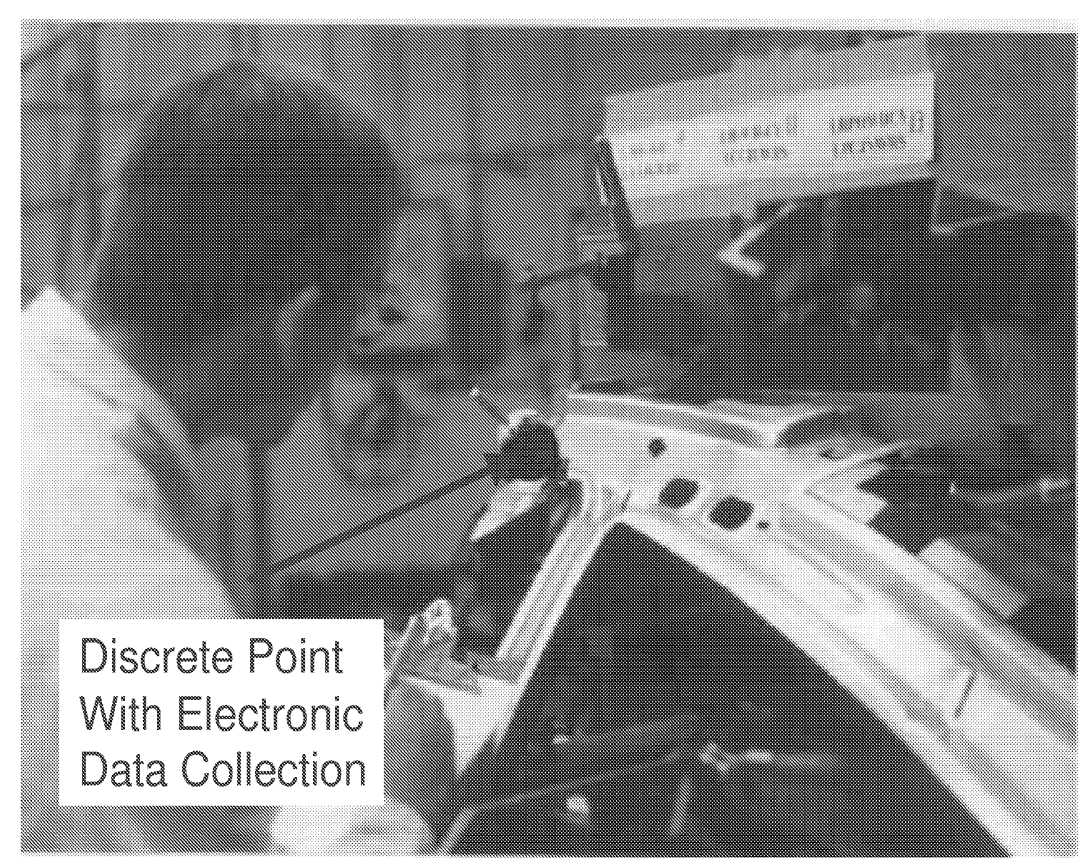

Figure 1. Sample Checking Fixture with Discrete Point Measurement Location

One concern with trying to minimize the number of discrete measurement locations is that a manufacturer may not fully comprehend potential problem areas. For instance, body manufacturing problems tend to arise in areas not being checked. In addition, some part characteristics such as flatness, parallelism of a mating surface, or trim edge consistency become very difficult to evaluate using discrete points, as each of these characteristics requires multiple 
discrete points to estimate. Another concern with discrete point checking systems is that a manufacturer may not be able to pre-define which discrete point locations are critical during the part design and development process. Thus, manufacturers often incur significant costs during the product lifecycle for adding, changing, or deleting discrete point locations.

One strategy that mitigates some of the above concerns is to utilize Coordinate Measuring Machine (CMM) inspection systems. CMMs provide greater flexibility by allowing adding/changing/deleting inspection points through programming, versus having to make hard tooling changes as required by traditional check fixtures with electronic data collection bushings. CMM inspection, however, is primarily just a more flexible discrete point measurement system. It has limited capability in evaluating complex part shapes and other characteristics such as consistency of an entire surface, part radii, or parallelism. For these particular features, it requires a significant number of pre-programmed discrete measurement points. For example, to fully comprehend a door assembly, a manufacturer using a CMM might require pre-programming 200-300 discrete point locations. Unfortunately, measuring a large data set with a CMM may take four to eight hours for a single part, and comprehensive information regarding the part shape still may not be fully represented. In addition, the engineering development and metrology resources needed to determine the desired $X, Y, Z$ location and the respective angle of measurement approach (often defined by an i,j,k approach vector) for a large CMM data set of a complex part often makes this activity cost prohibitive. Also of concern with CMM systems are the transportation costs associated with moving parts to a special inspection room.

These traditional check fixture and CMM limitations have resulted in the adoption of non-contact discrete point vision systems. These systems, made popular by Perceptron, are widely used for in-line measurement, particularly in automotive body shops to measure large body sides, underbodies, and main body assemblies. In-line vision systems usually incorporate either several fixed position cameras in a work cell or a few cameras mounted to robots. As an example, a full body might require four robots to access all of the discrete point locations. Historically, these systems have provided tremendous advantages in terms of ease of data collection for discrete point measurements. Still, they have limitations similar to CMMs in terms of their strong cost and time dependency on the number of discrete point locations. As a result, cost considerations often force manufacturers to measure fewer points than desired. 
Recently, the development of 3D non-contact measurement systems that generate point cloud data offers the potential to replace or augment these traditional discrete point checking systems (e.g., traditional hard tooling check fixtures, in-line vision systems, and CMM systems). These 3D non-contact point cloud systems offer the flexibility to measure the full part shape (or critical part areas) as well as provide measurements at discrete point locations which typically are necessary to satisfy data sampling requirements for process capability analysis studies. Figure 2 illustrates sample output from a 3D non-contact measurement system for a hood inner panel using the CogniTens' Optigo 200. For this particular example, only certain areas of the part were measured, as indicated by the colored areas. In addition, the colored balls represent discrete point locations, whereas the remaining areas represent clouds of points. These clouds of points illustrate the conformance of the part surface to the CAD design nominal values. Note: Dark blue and dark red represent areas with the largest deviations from nominal.

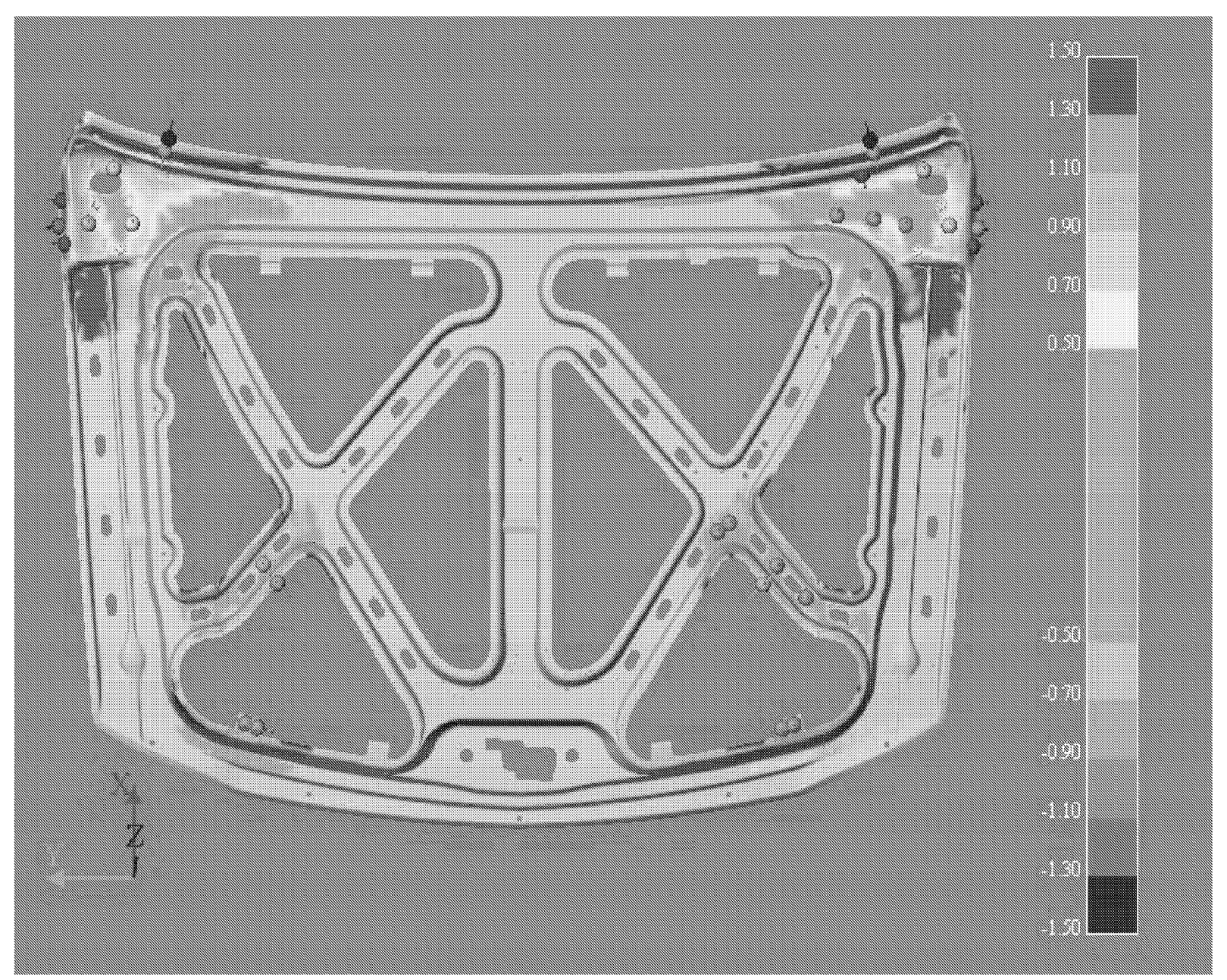

Figure 2. Sample Output from a CogniTens Optigo 200 System 
For automotive body applications, CMMs are the typical standard to which to compare new measurement technology systems. For instance, organizations using in-line vision systems routinely calibrate their process measurements based on correlation studies with CMM systems. In fact, manufacturers commonly incorporate "mean offsets" in their in-line vision systems to correlate the mean dimensions from the in-process inspection studies to their CMM reports. This practice is common because differences in measurement algorithms and the physical tooling locators used to hold parts during measurement can result in inherent mean biases between systems. The need for these "mean offsets" due to inherent fixture biases represents another measurement system challenge. Although these mean offsets are typically related to fixture differences rather than limitations of vision system technology, most companies desire new technology that matches CMM performance in terms of measurement system variation capability and mean consistency (i.e., to reduce the need for mean offsets).

The purpose of this paper is to assess the measurement system capability of a 3D noncontact measurement system developed by CogniTens (the Optigo 200). This paper first includes a brief discussion of 3D non-contact measurement technology and several potential sources of measurement error in automotive body applications. Next, three case studies are used to assess the measurement system capability and make comparisons between the CMM and Optigo 200 . These case studies evaluate measurement system repeatability (both static and dynamic), reproducibility (thus, Gage R\&R) and feature correlation (i.e., measurement system accuracy and biases). The various sources of measurement system error also are by body measurement feature such as surface measurements, edge points, and hole positions.

\section{3D Non-Contact Measurement Technology and the CogniTens System}

Various systems have been developed for 3D non-contact measurement, such as laser scanners/trackers and photogrammetry-based systems. All of these systems involve the use of structured light to generate part measurements. Gershon and Benady [1] and Mitchell [2] provide overviews of these systems and a more detailed discussion of the various technologies.

One of these 3D systems, developed by CogniTens, involves the use of three high resolution CCD (Charge Coupled Device) cameras with indirect photogrammetry to obtain multiple 2D image projections. These projections, obtained in tiles (approximately $300-600 \mathrm{~mm}$ 
in length and width), are then "stitched" together to provide a part shape representation. The amount of stitching is based on the relationship between the size of the part and the tile's field of view size. In general, smaller relative tile sizes provide more accurate readings.

The time to measure a complete part with the Optigo system is dependent on the relationship between the part size and the tile size. In some instances, a manufacturer may be interested only in a portion of the full part shape, which reduces the measurement time. For example, a manufacturer may wish to measure along the critical mating flange surface of a stamped part. In general, a complex part such as a body side may be comprehensively measured in less than an hour using the portable, manual system. This time may be reduced to less than one minute with more automated systems or holding fixture enhancements.

In measuring a part, the Optigo system uses coded targets either on the part or integrated into the part holding fixture to align measurements relative to a single global coordinate system (see Figure 3). The process of establishing a coordinate system from the targets is known as mapping. For automotive body measurement applications, the mapping process is integral to providing accurate and repeatable part measurement data. Once the global coordinate system is established, part measurements may then be compared to either part CAD model nominal dimensions or relative to other parts within a sample. Section 4 provides an evaluation of the mapping process, which is critical in comparing the measurement system capability and correlation between the CMM and the Optigo system under typical factory conditions.

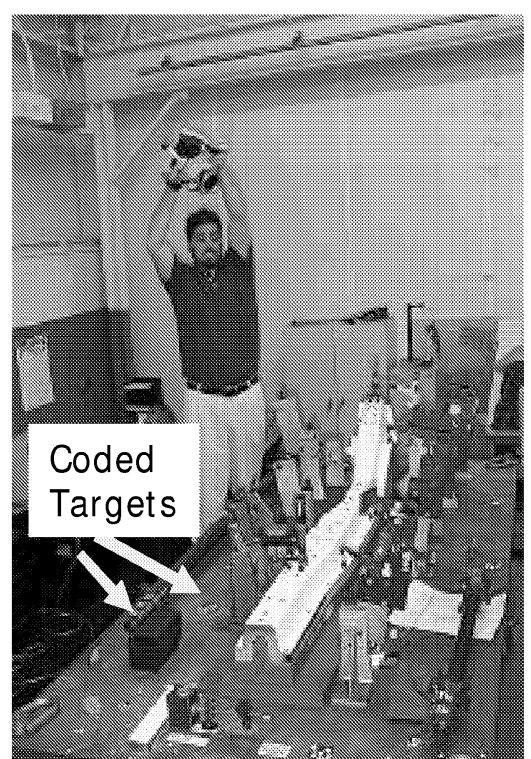

Figure 3. Measuring a Stamping Rail Panel Using Targets 
The Optigo 3D non-contact measurement system generates point cloud data, which consists of thousands of point measurements meshed together to represent a full part shape. Figure 4 shows the measurement results for the rail part used in the first case study. From these measurement data, we may clearly see that while most of the panel is within specification (shown by the green areas), certain localized areas have large deviations from nominal. For instance, one end of the rail panel is significantly low relative to body position (indicated by the dark blue area), while another mating weld surface has a bow or high spot (shown in red). From an assembly standpoint, a low surface may result in an interference with its mating panel. This interference could result in excess assembly variation due to crashing panels. For the other nonconforming area, the localized bow could result in an excess gap when trying to weld this mating surface to its adjoining component. In other words, if a weld is required in this localized area, this surface bow could require excessive pulling of the metal during welding, which ultimately could result in an assembly twist. Historically, manufacturers have not had access to this level of detail in evaluating stamping and subassembly parts. As a result, parts that may appear inspecification per their discrete measurement point inspection data could in fact be causing downstream assembly problems.

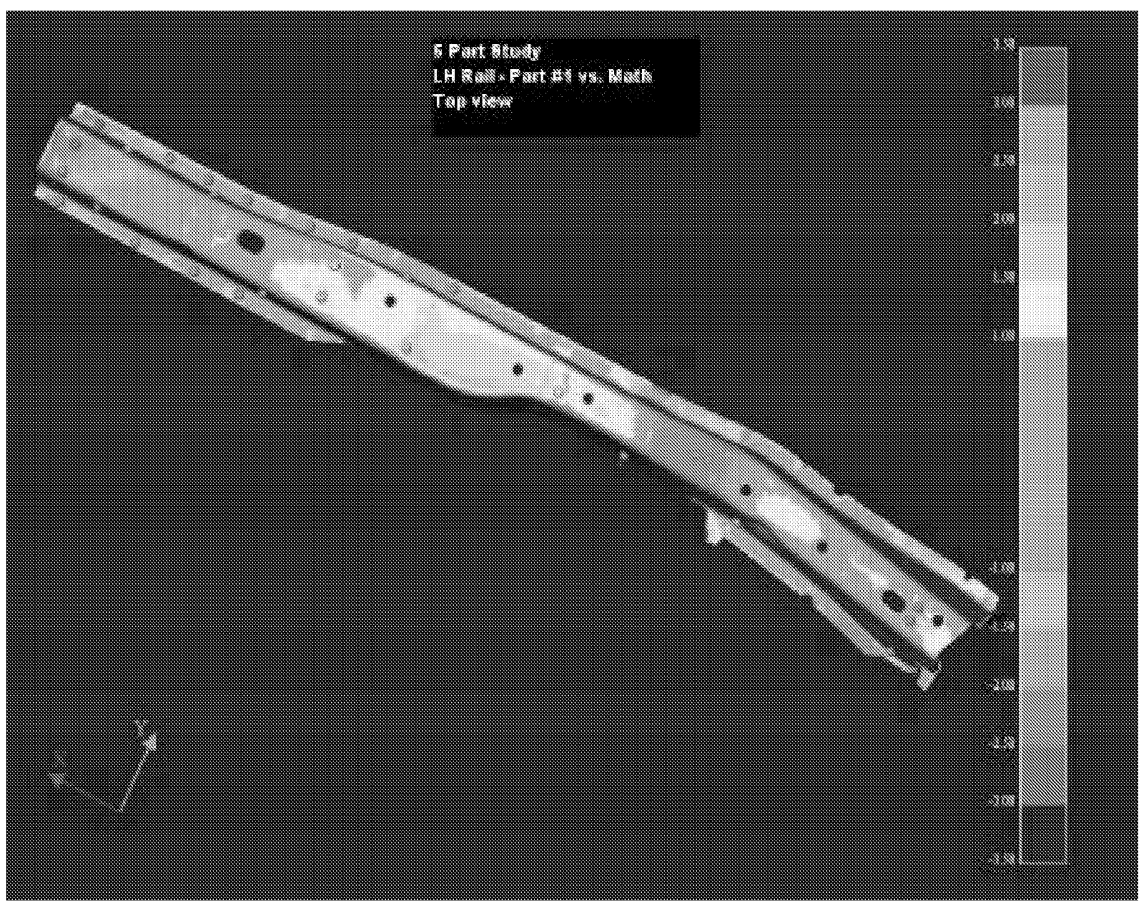

Figure 4. Measurement Results Relative to CAD Design Nominals 
One potential concern with using point cloud data is over-reaction or over-adjustment to non-conforming areas of a part. For instance, even though a local bow exists in the rail part shown earlier, it may have no effect on the assembly process. Thus, even with point cloud data, manufacturers will likely need to utilize physical functional evaluations or assembly slow builds to determine if these localized deviations are actually causing assembly concerns. Still, having point cloud data significantly enhances diagnostic ability particularly when trying to determine if an assembly concern is attributed to variability in its components or related to the manufacturing process.

In addition to point cloud data, the Optigo 200 system may be used to measure at discrete point locations. These discrete point measurements may be compared to those made by other discrete point checking systems. One advantage of the Optigo system is that discrete point measurements may be made pre- or post-inspection. For instance, a manufacturer may retroactively measure the deviation at a particular discrete point location once a full point cloud data set is available. Figure 5 illustrates a section of the hood inner panel shown earlier with both discrete and full surface measurements.

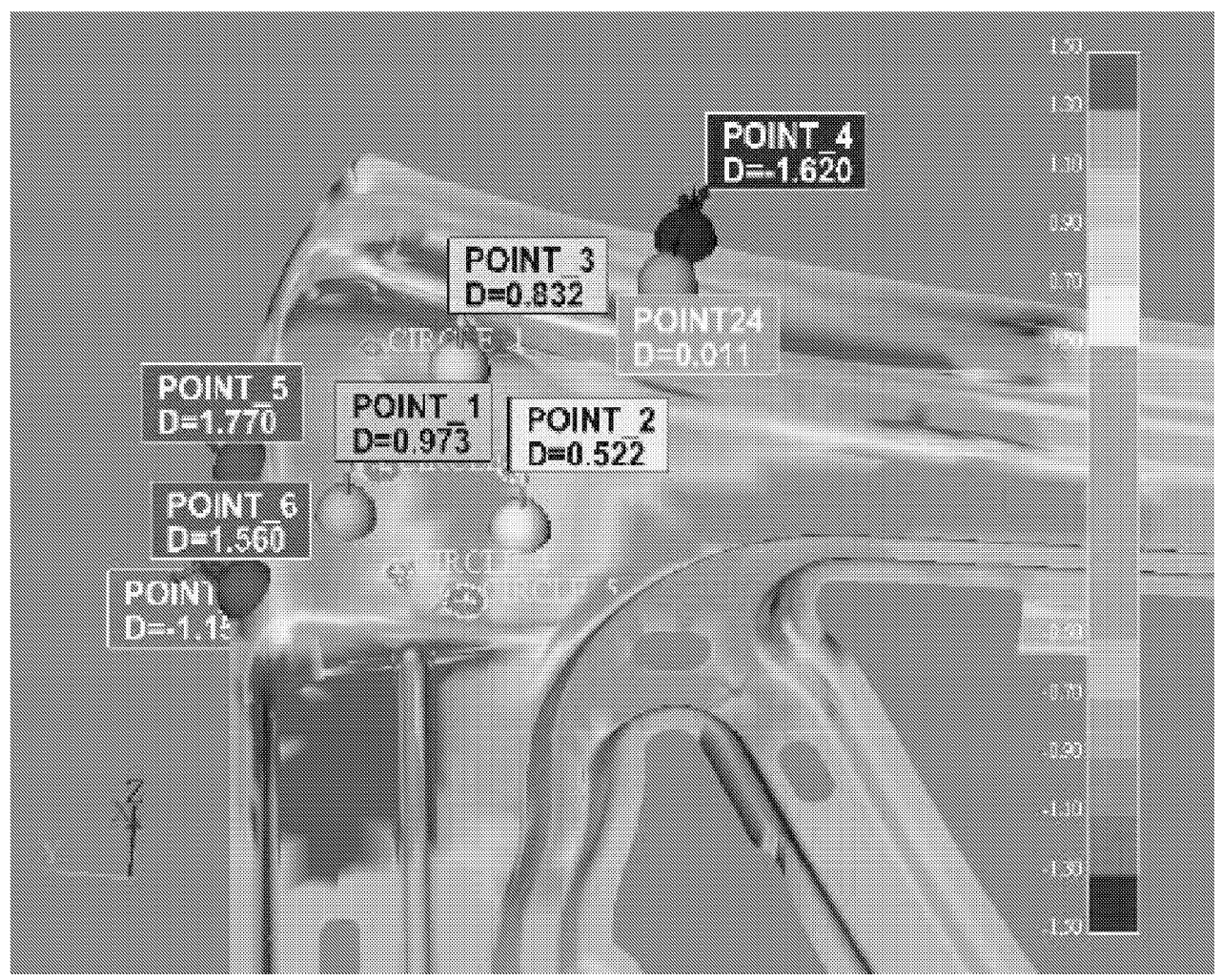

Figure 5. Hood Inner Panel Measurement Results with Discrete Points 
Although the focus of this report examines the portable, manually operated Optigo 200 system typically used for off-line inspection, similar technology is available for automated or inline measurement applications. Here, the Optigo system may be integrated with a robot to provide an automated measuring process.

\section{Potential Sources of Measurement Variation}

The capability of a measurement system is typically characterized by its accuracy and measurement error. The term measurement system error is often preferred over gage error because other factors beyond the gage itself may contribute to the variation. The three most common metrics used to assess measurement system capability are repeatability, reproducibility, and accuracy.

Measurement system repeatability represents the random variation in measurements when one operator uses the same gage to measure the same parts multiple times. Repeatability is occasionally separated into static and dynamic repeatability. Static repeatability is determined by repeatedly measuring a part in its holding fixture without loading and unloading between trials. Reproducibility represents the variation in average measurements made by different operators using the same gage and the same parts. The combination of repeatability and reproducibility is often referred to as $R \& R$ or Gage $R \& R$.

Measurement system accuracy is typically determined by comparing the observed average from a sample of parts using a specific measurement device to a "true" or "master" measurement determined from a more precise gage. Thus, the "true" average may be viewed as the standard that a measurement device is trying to replicate. Since CMM measurements are typically considered the most accurate method of body measurement, we will use them as the standard to compare to the Optigo system. Figure 6 illustrates these three types of measurement system variability.
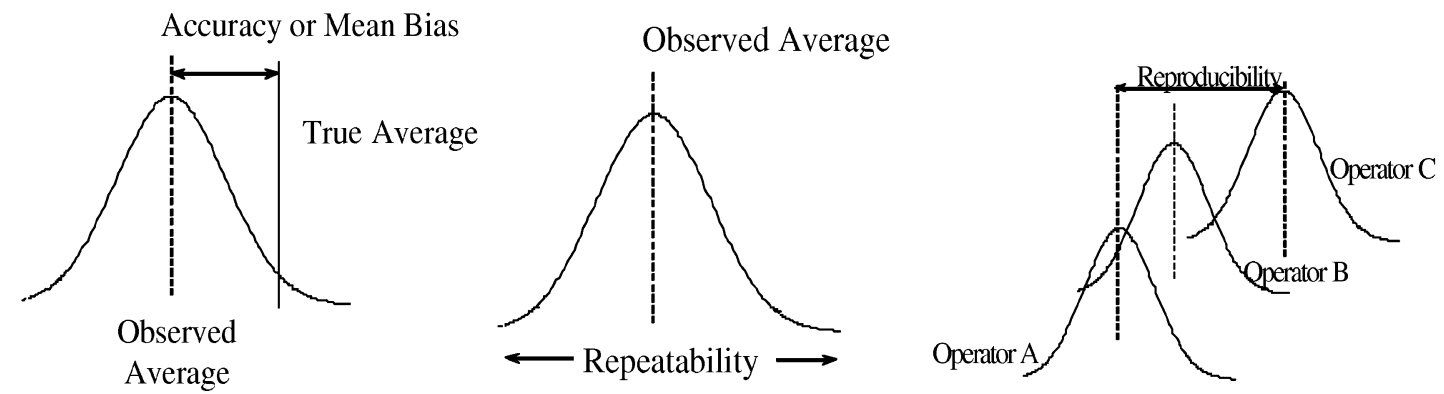

Figure 6. Accuracy, Repeatability, and Reproducibility 
Most manufacturers evaluate gage repeatability and reproducibility (Gage R\&R) using ratios between the measurement system variation $(R \& R)$ and the part variation and/or the tolerance width (see [3] -- "Measurement System Analysis: Reference Manual"). Most industries use the following set of equations to assess the contribution of repeatability, reproducibility, and their combined R\&R. (Note: In some industries, the 5.15 is replaced by 6 to represent $99.73 \%$ of a population of measurements instead of $99 \%$ ).

$$
\begin{gathered}
\% \mathrm{EV}-\text { Tolerance }=\frac{5.15 \sigma_{\text {repeatabity }}}{U S L-L S L} \\
\% \mathrm{AV}-\text { Tolerance }=\frac{5.15 \sigma_{\text {reproducibility }}}{U S L-L S L} \\
\% \mathrm{R} \& \mathrm{R}-\text { Tolerance }=\frac{5.15 \sigma_{R \& R}}{U S L-L S L}
\end{gathered}
$$

Another technique to evaluate the contribution of the measurement error component is to assess the ratio of the measurement system variance relative to the observed part variance. The following equations represent formulas to assess this percentage contribution.

$$
\begin{aligned}
& \text { \%repeatability }=\frac{\sigma_{\text {repeatability }}^{2}}{\sigma_{\text {part }}^{2}} ; \\
& \% \text { reproducibility }=\frac{\sigma_{\text {reproducibility }}^{2}}{\sigma_{\text {part }}^{2}} ; \\
& \% R \& R=\frac{\sigma_{R \& R}^{2}}{\sigma_{\text {part }}^{2}}
\end{aligned}
$$

Alternatively, the contribution of the $R \& R$ variation may be related to the part variation

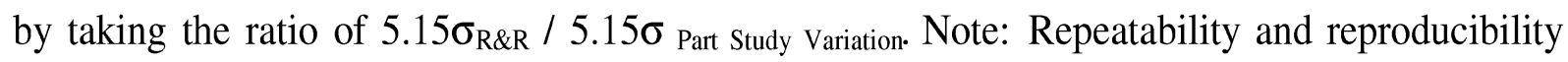
may be examined as well by using $5.15 \sigma_{\text {repeatability }} / 5.15 \sigma$ Part Study Variation and $5.15 \sigma_{\text {reproducibility }} /$

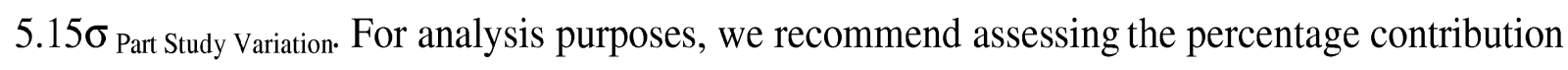
of the variance as the more appropriate comparison. Repeatability and reproducibility variances

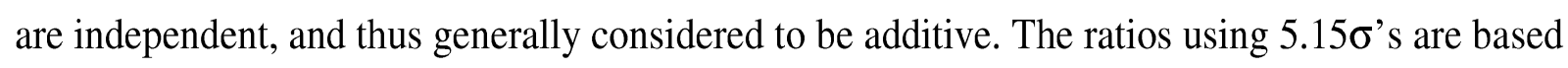
on standard deviations, which are not additive. 
For automotive body component dimensions, typical tolerances used for part features range from $\pm 0.5 \mathrm{~mm}$ to $\pm 1.5 \mathrm{~mm}$. In terms of part variation, typical estimates for the inherent standard deviation of a stamping dimension, $\sigma_{\text {part }}$, ranges from 0.1 to $0.25 \mathrm{~mm}$. To provide a more robust comparison between the various part and dimensional studies conducted in this report, we use typical tolerances and historical estimates of part variation rather than observed study part variation. This provides a more representative comparison since the amount of observed variation among the part samples used varies by case study.

Measurement equipment providers often assess measurement system sources of variation by measuring known artifacts. For instance, manufacturers first would obtain highly precise manufactured gage blocks or other objects, such as cones or spheres, with known dimensions. Next, they would measure the accuracy and repeatability of their systems based on the "known" dimensions of the artifacts. Although this approach clearly provides a measure of the inherent or pure accuracy and repeatability of a measurement system, it may not necessarily reflect the capability of the system to evaluate production parts under normal manufacturing conditions.

Automotive body inspection is complicated because measurements typically are measured relative to a global coordinate system. This global coordinate system allows any discrete point to be defined by a unique three-dimensional XYZ location relative to a master body position (see Figure 7 for an example of a global body coordinate system). This global coordinate system is necessary to measure parts relative to a part's CAD design nominal dimensions. Thus, for CMM and other 3D non-contact systems, the initial setup of a measurement system and its alignment to a global coordinate system provide potential sources of measurement error.

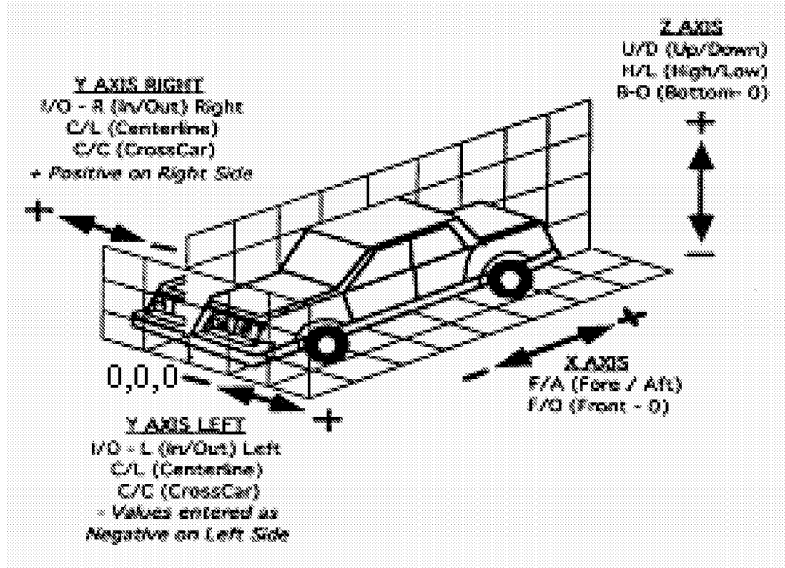

Figure 7. Global Body Coordinate System (Front, Center, Bottom: 0,0,0) 
Automotive body component measurements also may be affected by the holding fixture used to secure and align a part during measurement [4]. Part holding fixtures typically utilize clamps and pins (often defined using Geometric Dimensioning and Tolerancing - GD\&T Standards for Datums) to repeatedly secure a part for measurement. Both the Optigo and CMM systems require alignment of the part holding fixture datums to the global coordinate system. Some common alignment methods include the use of tooling balls or fixture coordinates at assumed known XYZ locations in order to relate the fixtures to the global body coordinate system. Any time a measurement system (CMM or Optigo 200) loses its reference relationship to the global coordinate system, the system must be re-setup or re-aligned.

Thus, for complex-shaped automotive body panels, numerous factors may impact the measurement system capability including the gage, the fixtures used to hold parts during measurement, the global coordinate setup process, the measurement instructions, and the gage operators. Thus, rather than using artifacts, we use actual stamped parts to assess the measurement system capability and to determine if any significant differences exist between the Optigo system and the CMM. (Note: For each of the case studies presented in this report, we measure the same set of parts at specific discrete locations for both the CMM and Optigo.)

In assessing measurement system capability and correlation between systems, we may stratify our metrics by part feature type. The feature types examined in this report include surface points, trim edges, and hole positions. Figure 8 illustrates various discrete measurement locations for the reinforcement part used in the Gage R\&R case study. These features are designated by surface point, trim edge, and hole. In evaluating hole positions, we also examine various algorithms used by manufacturers to determine the center location.

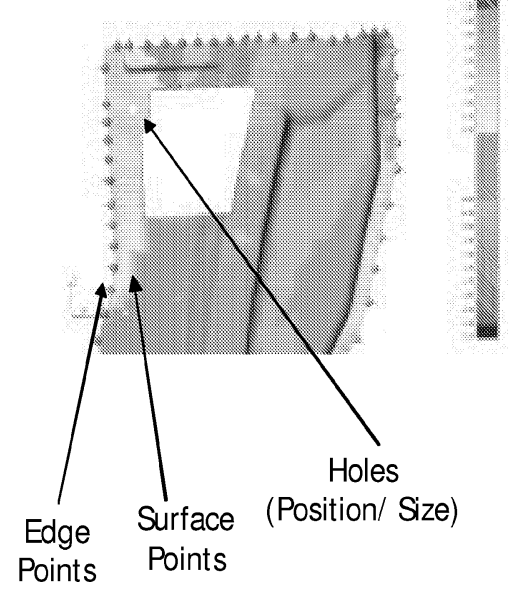

Figure 8. Part Feature Types 


\section{Measurement System Analysis Case Studies}

To evaluate the various sources of measurement variation with the Optigo 200, we created three case studies. The first case study involved a rear compartment side rail and is used to evaluate the Optigo mapping process and static repeatability. Next, we used a structural reinforcement panel to compare Gage R\&R between systems. Finally, we studied a more complex hood inner panel to evaluate accuracy and correlation of specific part features between the Optigo and CMM systems.

\subsection{Mapping Process Measurement Error and Static Repeatability}

The Optigo 200 uses a mapping process to align the measuring device with the fixture prior to recording measurements. Mapping involves the use of coded targets placed on the part or on the fixture to establish a coordinate reference system. In terms of potential measurement error, mapping is similar to the CMM fixture alignment setup process. Here, when a part holding fixture is placed on a CMM plate, the CMM must align the fixture to a global coordinate system in order to measure deviations relative to body coordinates. For purposes of this report, we refer to the mapping effect consistency as $\sigma_{\text {fixture-mapping. }}$

To evaluate the fixture mapping alignment effect of the Optigo process, we studied a rear compartment side rail, measuring 43 dimensions on five panel samples. For each panel, we conducted two different mappings prior to measurement. In addition, we measured panels twice during each mapping without removing the part from the fixture. Figure 9 illustrates the experimental combinations in the study.

\section{Rail Study}

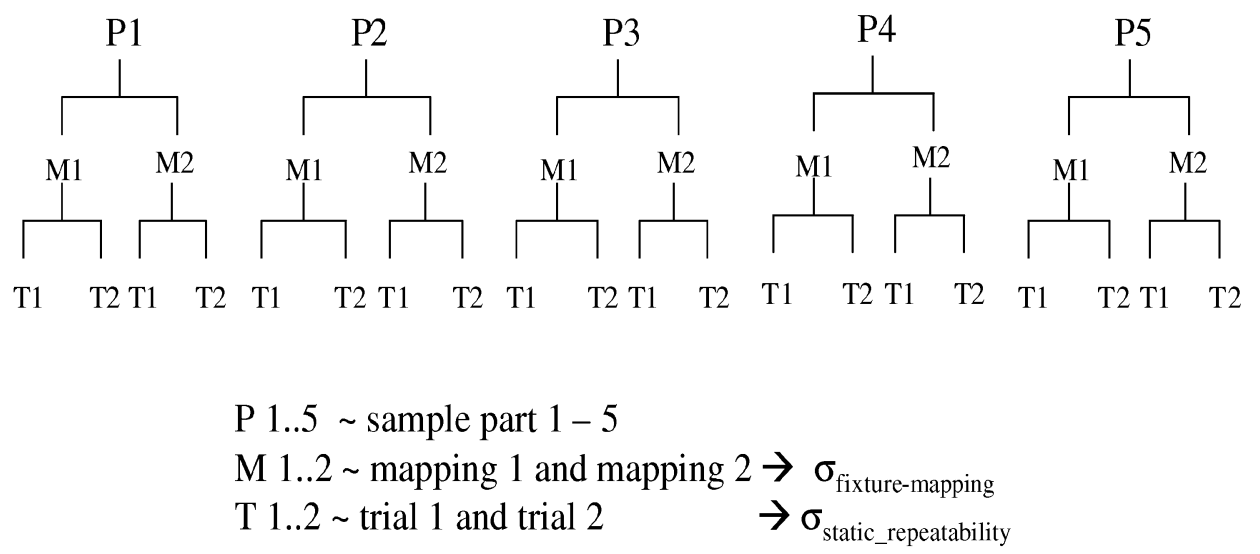

Figure 9. Rail Study: Mapping Effect and Static Repeatability 
From this study, we may estimate two components of measurement variation, the fixture mapping effect and the static repeatability. Static repeatability represents the pure measurement system repeatability without the load and unload operation of a part in a fixture. In other words, static repeatability represents the pure repeatability error of the measuring device. A typical Gage Repeatability Study involves loading and unloading parts between trials. Thus, static repeatability represents one variation component of measurement system repeatability.

Table 1 summarizes the mapping process effect for the 43 dimensions by feature type and Figure 10 illustrates the location of several dimensions. Overall, the potential measurement error due to mapping is quite small. The average $\sigma_{\text {fixture-mapping }}$ is only 0.004 with a $95^{\text {th }}$ percentile of 0.013. For automotive body component applications, a low-end tolerance requirement is $+/-0.5$ $\mathrm{mm}$ with a part variation, $\sigma_{\text {part }}$, requirement of less than 0.15 . Based on these values, the mapping effect variance would, in a poor condition, only account for about $1 \%$ of part variance (calculated using $\sigma_{\text {fixture-mapping }}{ }^{2} / \sigma_{\text {part }}^{2}$ ), and only $7 \%$ of measurement error relative to tolerance (assumes a $+/-0.5 \mathrm{~mm}$ tolerance and is calculated using Percentage Fixture Effect $=5.15 \sigma_{\text {fixture- }}$ mapping / Tolerance Width).

\begin{tabular}{|l|c|c|c|}
\hline & $\#$ Dimensions & $\sigma_{\text {fixture-mapping }}$ & $5.15 * \sigma_{\text {fixture-mapping }}$ \\
\hline Average-Hole Position & 5 & 0.006 & 0.033 \\
\hline Average-Surface Points & 25 & 0.004 & 0.023 \\
\hline Average-Edge Points & 13 & 0.002 & 0.009 \\
\hline & & & \\
\hline Average-All & 43 & 0.004 & 0.020 \\
\hline 95th Percentile-All & & 0.013 & 0.065 \\
\hline
\end{tabular}

Table 1. Fixture Mapping Effect

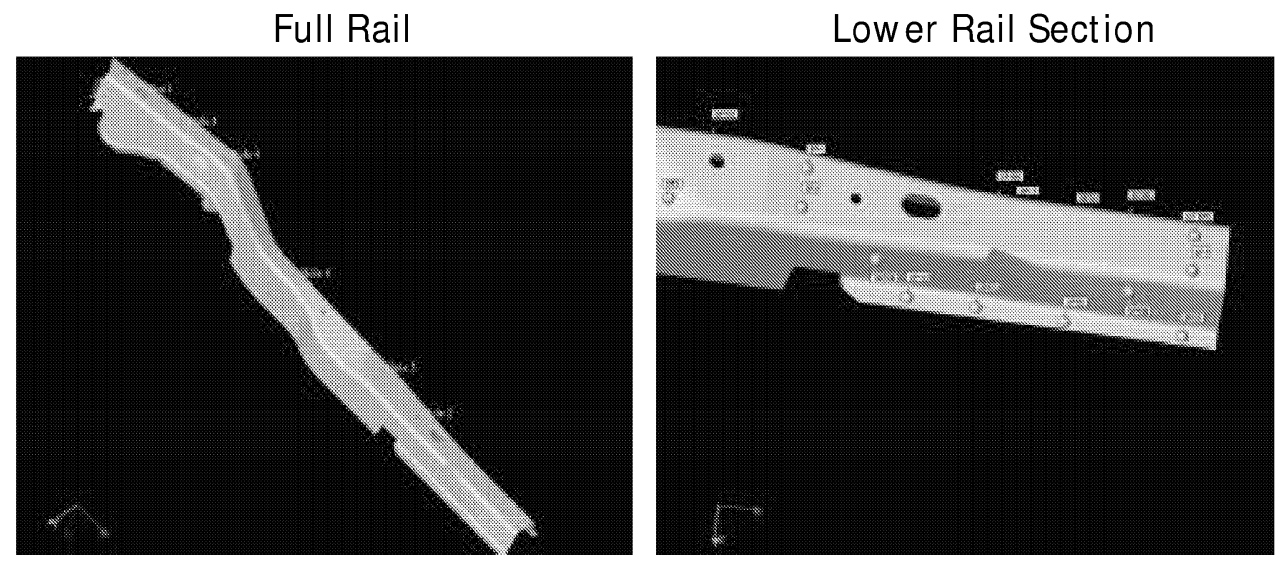

Figure 10. Rail Measurements 
In this study, we measured each part twice per mapping without unloading it from the fixture. Thus, we may also assess the static repeatability of the system. Compared with the mapping effect, the potential measurement error due to static repeatability is more significant. The average $\sigma_{\text {static_repeatability }}$ for the parts was 0.017 with a $95^{\text {th }}$ percentile of 0.028 (see Table 2 ). Again, we may compare these results to a low-end tolerance value of $\pm 0.5 \mathrm{~mm}$ and a part variation target, $\sigma_{\text {part }}$ of 0.15 . Based on these desired values, the static repeatability variance would, at a worst condition, account for about $3.5 \%$ of part variance (based on $\sigma_{\text {static_repeatability }}{ }^{2} /$ $\sigma_{\text {part }}{ }^{2}$ ) and $14 \%$ of measurement error relative to a $\pm 0.5 \mathrm{~mm}$ tolerance (i.e., based on 5.15 $\sigma_{\text {static_repeatability }} /$ Tolerance Width). Note: Using average $\sigma_{\text {static_repeatability values instead of the } 95^{\text {th }}}$ percentile condition, the Optigo 200 system would account for about $9 \%$ of the tolerance width, assuming a tolerance of $\pm 0.5 \mathrm{~mm}$.

\begin{tabular}{|l|c|c|c|}
\hline & $\#$ Dimensions & $\sigma_{\text {static_repeatability }}$ & $5.15 * \sigma_{\text {static_repeatability }}$ \\
\hline Average-Hole Position & 5 & 0.011 & 0.057 \\
\hline Average-Surface Points & 25 & 0.017 & 0.088 \\
\hline Average-Edge Points & 13 & 0.019 & 0.098 \\
\hline & & & \\
\hline Average-All & 43 & 0.017 & 0.088 \\
\hline 95th Percentile-All & & 0.028 & 0.144 \\
\hline
\end{tabular}

Table 2. Static Repeatability Error (Note: Average CMM $\sigma_{\text {static }} \sim 0.007$ )

The static repeatability of the Optigo 200 system was higher than another study involving CMM systems. In a different study of CMM static repeatability for a body side outer panel, the average static repeatability observed was 0.007 with a $95^{\text {th }}$ percentile of 0.015 [5] (versus 0.017 and 0.028 for the Optigo). One explanation for the higher static repeatability in the Optigo 200 system is that the Optigo does not perform a physical measurement directly along an ijk vector. With CMM measurements, an ijk vector path is programmed along with an XYZ nominal position to determine the normal to surface path for the measurement probe of the CMM. With the Optigo system, this normal to surface vector path is calculated during the measurement process. 
Based on these data, static repeatability appears to be a greater concern for edge and surface points than for hole position measurements (see Table 3). We further explore the repeatability issue in our Gage $R \& R$ study (see section 4.2), where the repeatability error is compounded by including the part loading and unloading effect.

\begin{tabular}{|c|c|c|c|}
\hline $\begin{array}{c}\text { Discrete Point } \\
\text { Feature }\end{array}$ & $\sigma_{\text {static_repeatability }}$ & $\begin{array}{c}\text { Discrete Point } \\
\text { Feature }\end{array}$ & $\sigma_{\text {static_repeatability }}$ \\
\hline Surface Pt 1 & 0.015 & Hole 2 & 0.009 \\
\hline Surface Pt 2 & 0.014 & Hole 3 & 0.008 \\
\hline Surface Pt 3 & 0.007 & Hole 4 & 0.012 \\
\hline Surface Pt 4 & 0.009 & Hole 5 & 0.011 \\
\hline Surface Pt 5 & 0.012 & Hole 6 & 0.016 \\
\hline Surface Pt 6 & 0.009 & Edge Pt 1 & 0.027 \\
\hline Surface Pt 7 & 0.010 & Edge Pt 2 & 0.030 \\
\hline Surface Pt 8 & 0.010 & Edge Pt 3 & 0.028 \\
\hline Surface Pt 9 & 0.016 & Edge Pt 4 & 0.016 \\
\hline Surface Pt 10 & 0.019 & Edge Pt 5 & 0.017 \\
\hline Surface Pt 11 & 0.029 & Edge Pt 6 & 0.011 \\
\hline Surface Pt 12 & 0.028 & Edge Pt 7 & 0.016 \\
\hline Surface Pt 13 & 0.026 & Edge Pt 8 & 0.012 \\
\hline Surface Pt 14 & 0.024 & Edge Pt 9 & 0.014 \\
\hline Surface Pt 15 & 0.021 & Edge Pt 10 & 0.015 \\
\hline Surface Pt 16 & 0.013 & Edge Pt 110 & 0.018 \\
\hline Surface Pt 17 & 0.011 & Edge Pt 112 & 0.028 \\
\hline Surface Pt 18 & 0.017 & Edge Pt 113 & 0.016 \\
\hline Surface Pt 19 & 0.016 & & \\
\hline Surface Pt 20 & 0.014 & & \\
\hline Surface Pt 105 & 0.027 & & \\
\hline Surface Pt 106 & 0.016 & & \\
\hline Surface Pt 107 & 0.024 & & \\
\hline Surface Pt 108 & 0.026 & & \\
\hline Surface Pt 109 & 0.018 & & \\
\hline
\end{tabular}

Table 3. Static Repeatability Error by Feature Type (Rail Part)

\subsection{Gage Repeatability and Reproducibility Analysis}

To evaluate measurement system repeatability and reproducibility, we conducted a $5 \times 2 \times 2$ Gage R\&R study for a structural reinforcement panel using both the CMM and the Optigo 200. A 5x2x2 study involves five parts measured twice each by two different operators. Figure 11 shows this reinforcement panel and the discrete point locations used to assess the measurement system capability. In this analysis, we compare the various sources of measurement error relative to historical tolerance widths, historical estimates of part variation, and the actual observed study variation. 


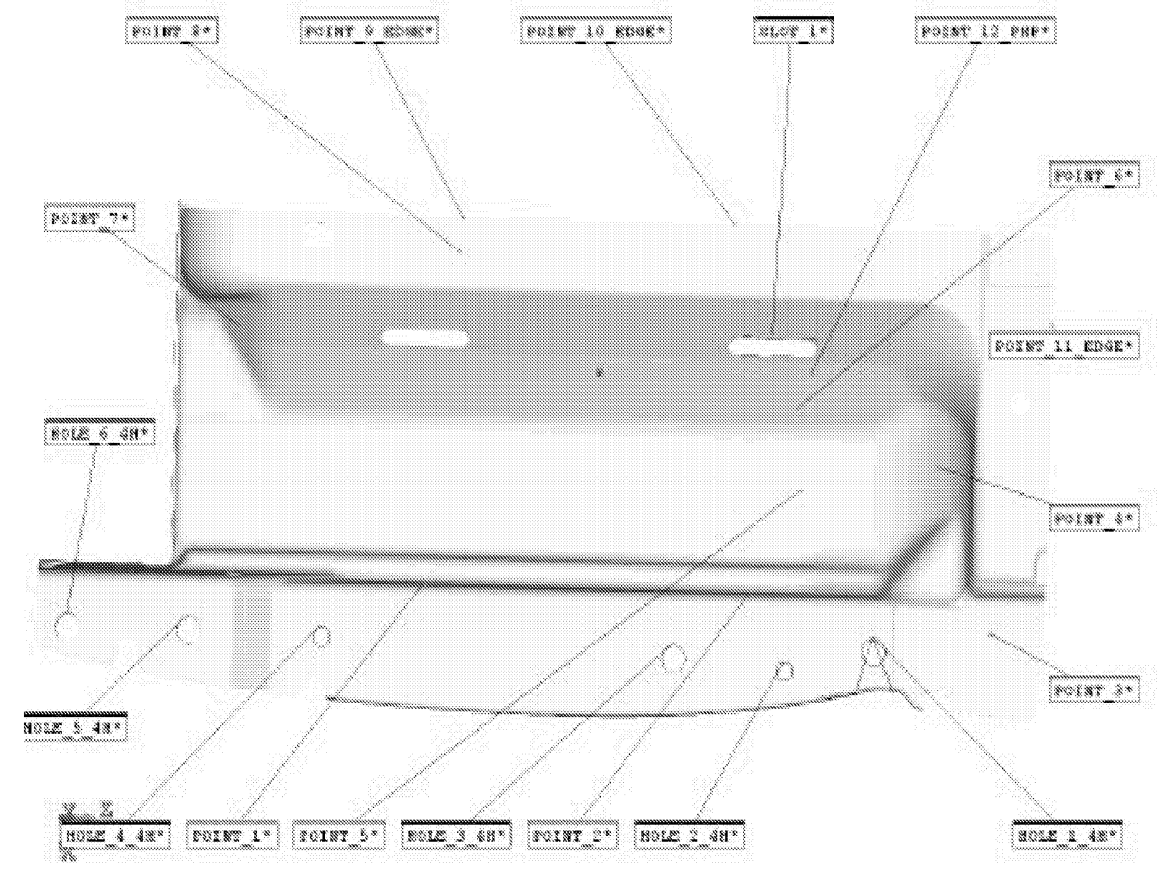

Figure 11. Structural Reinforcement Panel with Discrete Point Dimensions

Table 4 summarizes the observed repeatability, reproducibility, and total Gage R\&R for each of the discrete points examined. In this study, we examine three edge points, six hole positions, and nine surface points. Overall, the CMM slightly outperformed the Optigo system. The $95^{\text {th }}$ percentile $\sigma_{R \& R}$ is 0.063 for the Optigo and 0.050 for the CMM.

\begin{tabular}{|l|c|c|c|c|c|c|c|c|}
\hline & Optigo & CMM & Optigo & CMM & Optigo & CMM & Optigo & CMM \\
\hline \multicolumn{1}{|c|}{ Dimension } & $\sigma_{\text {repeatability* }}$ & $\sigma_{\text {repeatability* }}$ & $\sigma_{\text {reproducibility* }}$ & $\sigma_{\text {reproducibility* }}$ & $\sigma_{\text {R\&R }}$ & $\sigma_{\text {R\&R }}$ & $5.15 * \sigma_{\text {R\&R }}$ & $5.15 * \sigma_{\text {R\&R }}$ \\
\hline Hole 1 & 0.044 & 0.014 & 0.000 & 0.021 & 0.044 & 0.025 & 0.227 & 0.130 \\
\hline Hole 2 & 0.050 & 0.013 & 0.039 & 0.022 & 0.063 & 0.025 & 0.325 & 0.129 \\
\hline Hole 3 & 0.042 & 0.013 & 0.000 & 0.023 & 0.042 & 0.026 & 0.217 & 0.135 \\
\hline Hole 4 & 0.042 & 0.013 & 0.032 & 0.021 & 0.053 & 0.025 & 0.271 & 0.128 \\
\hline Hole 5 & 0.035 & 0.012 & 0.026 & 0.023 & 0.044 & 0.026 & 0.225 & 0.133 \\
\hline Hole 6 & 0.041 & 0.014 & 0.018 & 0.019 & 0.044 & 0.024 & 0.228 & 0.122 \\
\hline SP1 & 0.027 & 0.017 & 0.000 & 0.010 & 0.027 & 0.020 & 0.139 & 0.100 \\
\hline SP2 & 0.043 & 0.029 & 0.048 & 0.051 & 0.064 & 0.059 & 0.332 & 0.302 \\
\hline SP3 & 0.034 & 0.028 & 0.027 & 0.000 & 0.044 & 0.028 & 0.225 & 0.145 \\
\hline SP4 & 0.017 & 0.009 & 0.008 & 0.008 & 0.019 & 0.012 & 0.095 & 0.060 \\
\hline SP5 & 0.032 & 0.018 & 0.021 & 0.003 & 0.038 & 0.019 & 0.196 & 0.096 \\
\hline SP6 & 0.024 & 0.007 & 0.000 & 0.008 & 0.024 & 0.011 & 0.125 & 0.055 \\
\hline SP7 & 0.026 & 0.016 & 0.000 & 0.013 & 0.026 & 0.020 & 0.132 & 0.105 \\
\hline SP8 & 0.046 & 0.012 & 0.008 & 0.030 & 0.047 & 0.032 & 0.243 & 0.164 \\
\hline SP12 & 0.021 & 0.002 & 0.000 & 0.001 & 0.021 & 0.002 & 0.107 & 0.012 \\
\hline EP9 & 0.036 & 0.048 & 0.000 & 0.000 & 0.036 & 0.048 & 0.184 & 0.248 \\
\hline EP10 & 0.051 & 0.032 & 0.000 & 0.000 & 0.051 & 0.032 & 0.262 & 0.165 \\
\hline EP11 & 0.030 & 0.025 & 0.000 & 0.000 & 0.030 & 0.025 & 0.152 & 0.130 \\
\hline
\end{tabular}


Table 4. Full Gage R\&R Comparison: CMM vs. Optigo

Although the CMM outperformed the CogniTens system in terms of magnitude of measurement system error, the practical impact of this difference is relatively minor. If we equate the gage error estimates relative to our various metrics (percentage of historical part variance and percentage of tolerance), we notice that the difference is marginal relative to industry criteria for acceptability (see Table 5). For these data, both the CMM and the Optigo would pass a Gage R\&R study using the typical criteria which seeks a Percentage Gage R\&R Tolerance $<30 \%$. However, we should note that the repeatability concern could potentially affect Gage R\&R pass rates for dimensions with tight tolerances, even though the percentage of part variance explained by repeatability would be relatively low.

\begin{tabular}{|l|c|c|c|c|}
\hline & \multicolumn{2}{|c|}{ Historical $\sigma_{\text {part }}=0.15 \mathrm{~mm}$} & \multicolumn{2}{c|}{ Tolerance width $=1.0(+/-0.5) \mathrm{mm}$} \\
\hline & Optigo & $\mathbf{C M M}$ & Optigo & $\mathbf{C M M}$ \\
\hline Dimension & $\sigma_{\text {R\&R }}^{2} / \sigma_{\text {part }}^{2}$ & $\sigma_{\text {R\&R }}^{2} / \sigma_{\text {part }}^{2}$ & $\%$ R\&R - Tol & $\%$ R\&R - Tol \\
\hline Hole 1 & $8.6 \%$ & $2.8 \%$ & $23 \%$ & $13 \%$ \\
\hline Hole 2 & $17.7 \%$ & $2.8 \%$ & $32 \%$ & $13 \%$ \\
\hline Hole 3 & $7.9 \%$ & $3.1 \%$ & $22 \%$ & $14 \%$ \\
\hline Hole 4 & $12.3 \%$ & $2.7 \%$ & $27 \%$ & $13 \%$ \\
\hline Hole 5 & $8.5 \%$ & $3.0 \%$ & $23 \%$ & $13 \%$ \\
\hline Hole 6 & $8.7 \%$ & $2.5 \%$ & $23 \%$ & $12 \%$ \\
\hline SP1 & $3.2 \%$ & $1.7 \%$ & $14 \%$ & $10 \%$ \\
\hline SP2 & $18.4 \%$ & $15.3 \%$ & $33 \%$ & $30 \%$ \\
\hline SP3 & $8.4 \%$ & $3.5 \%$ & $22 \%$ & $14 \%$ \\
\hline SP4 & $1.5 \%$ & $0.6 \%$ & $10 \%$ & $6 \%$ \\
\hline SP5 & $6.4 \%$ & $1.5 \%$ & $20 \%$ & $10 \%$ \\
\hline SP6 & $2.6 \%$ & $0.5 \%$ & $13 \%$ & $5 \%$ \\
\hline SP7 & $2.9 \%$ & $1.8 \%$ & $13 \%$ & $10 \%$ \\
\hline SP8 & $9.9 \%$ & $4.5 \%$ & $24 \%$ & $16 \%$ \\
\hline SP9 & $1.9 \%$ & $0.0 \%$ & $11 \%$ & $1 \%$ \\
\hline EP1 & $5.7 \%$ & $10.3 \%$ & $18 \%$ & $25 \%$ \\
\hline EP2 & $11.5 \%$ & $4.6 \%$ & $26 \%$ & $16 \%$ \\
\hline EP3 & $3.9 \%$ & $2.8 \%$ & $15 \%$ & $13 \%$ \\
\hline
\end{tabular}

\begin{tabular}{|l|c|c|c|c|}
\hline Average-ALL & $8 \%$ & $4 \%$ & $20 \%$ & $13 \%$ \\
\hline 95th Percentile-ALL & $18 \%$ & $11 \%$ & $33 \%$ & $26 \%$ \\
\hline
\end{tabular}

Table 5. Gage R\&R Relative to Historical Variation and Tolerances

In the automotive industry, measurement system capability occasionally is measured by comparing the predicted range $\left(5.15^{*} \sigma_{R \& R}\right)$ with the observed variation in the study. Table 6 
shows the results of such an analysis for these parts. Using this analysis methodology, numerous discrete points for both the Optigo and CMM would fail the $30 \%$ desired criteria. The reason for this finding is that the observed standard deviation for the dimensions in this study is quite low. For instance, approximately half of the dimensions had standard deviations less than $0.15 \mathrm{~mm}$. In other words, for small levels of standard deviation, both the CMM and Optigo would have difficulty separating gage variation from these levels of observed part variation.

\begin{tabular}{|l|c|c|c|c|c|c|}
\hline & Optigo & CMM & Optigo & CMM & Optigo & CMM \\
\hline \multicolumn{1}{|c|}{ Dimension } & $\sigma_{\text {R\&R }}$ & $\sigma_{\text {R\&R }}$ & $\sigma_{\text {Study }}$ & $\sigma_{\text {Study }}$ & $5.15 \sigma_{\text {R\&R }} /$ & $5.15 \sigma_{\text {R\&R }}$ \\
& 0.044 & 0.025 & 0.081 & 0.042 & $55 \%$ & $60 \%$ \\
\hline Hole 1 & 0.063 & 0.025 & 0.081 & 0.043 & $78 \%$ & $58 \%$ \\
\hline Hole 2 & 0.042 & 0.026 & 0.081 & 0.041 & $52 \%$ & $65 \%$ \\
\hline Hole 3 & 0.053 & 0.025 & 0.126 & 0.041 & $42 \%$ & $61 \%$ \\
\hline Hole 4 & 0.044 & 0.026 & 0.167 & 0.044 & $26 \%$ & $59 \%$ \\
\hline Hole 5 & 0.044 & 0.024 & 0.177 & 0.041 & $25 \%$ & $58 \%$ \\
\hline Hole 6 & 0.027 & 0.020 & 0.083 & 0.074 & $33 \%$ & $26 \%$ \\
\hline SP1 & 0.064 & 0.059 & 0.099 & 0.116 & $65 \%$ & $51 \%$ \\
\hline SP2 & 0.044 & 0.028 & 0.076 & 0.067 & $58 \%$ & $42 \%$ \\
\hline SP3 & 0.019 & 0.012 & 0.062 & 0.045 & $30 \%$ & $26 \%$ \\
\hline SP4 & 0.038 & 0.019 & 0.051 & 0.037 & $75 \%$ & $50 \%$ \\
\hline SP5 & 0.024 & 0.011 & 0.061 & 0.056 & $40 \%$ & $19 \%$ \\
\hline SP6 & 0.026 & 0.020 & 0.072 & 0.070 & $35 \%$ & $29 \%$ \\
\hline SP7 & 0.047 & 0.032 & 0.064 & 0.071 & $74 \%$ & $45 \%$ \\
\hline SP8 & 0.021 & 0.002 & 0.026 & 0.016 & $79 \%$ & $15 \%$ \\
\hline SP9 & 0.036 & 0.048 & 0.061 & 0.069 & $59 \%$ & $69 \%$ \\
\hline EP1 & 0.051 & 0.032 & 0.065 & 0.069 & $78 \%$ & $47 \%$ \\
\hline EP2 & 0.030 & 0.025 & 0.067 & 0.036 & $44 \%$ & $70 \%$ \\
\hline EP3 & \multicolumn{7}{|l|}{} & 0.025 & & & \\
\hline
\end{tabular}

Table 6. Gage R\&R Relative to Observed Study Variation

We may use these estimates for repeatability and full Gage $R \& R$ to estimate the tolerances and part variance that could be measured using an $18 \%$ desired goal for repeatability or a $30 \%$ desired goal for R\&R [3]. Table 7 summarizes these results. Overall, we would expect the Optigo system to pass Gage $R \& R$ requirements for typical tolerances ranging from \pm 0.3 and \pm 0.7 (again, based on meeting the $30 \%$ criteria). We also may assess the ability of the measurement system to separate gage variation from part variation by examining the ratio of the variances (i.e., compare $\sigma_{\mathrm{R} \& \mathrm{R}}^{2} / \sigma_{\text {part }}^{2}<30 \%$ ). Based on this study, the Optigo system is capable of 
separating gage variation from part variation for inherent part sigma levels of $0.07 \mathrm{~mm}$ and higher. In comparison, CMM would be able to separate at standard deviation levels of 0.05.

\begin{tabular}{|l|c|c|c|c|}
\hline & $\begin{array}{c}\text { Optigo } \\
\text { Repeatability }\end{array}$ & $\begin{array}{c}\text { CMM } \\
\text { Repeatability }\end{array}$ & Optigo R\&R & CMM R\&R \\
\hline Average-ALL & 0.035 & 0.018 & 0.040 & 0.025 \\
\hline 95th Percentile-ALL & 0.050 & 0.034 & 0.063 & 0.050 \\
\hline
\end{tabular}

\begin{tabular}{|l|c|c|c|c|}
\hline Criteria & $18 \%$ & $18 \%$ & $30 \%$ & $30 \%$ \\
\hline Average Tolerance(+/-) & $\mathbf{0 . 5}$ & $\mathbf{0 . 3}$ & $\mathbf{0 . 3}$ & $\mathbf{0 . 2}$ \\
\hline 95th Percentile Tolerance & $\mathbf{0 . 7}$ & $\mathbf{0 . 5}$ & $\mathbf{0 . 5}$ & $\mathbf{0 . 4}$ \\
\hline Average Part Variation, $\sigma_{\text {part }}$ & $\mathbf{0 . 0 8}$ & $\mathbf{0 . 0 4}$ & $\mathbf{0 . 0 7}$ & $\mathbf{0 . 0 5}$ \\
\hline 95th Percentile Part Variation, $\sigma_{\text {part }}$ & $\mathbf{0 . 1 2}$ & $\mathbf{0 . 0 8}$ & $\mathbf{0 . 1 2}$ & $\mathbf{0 . 0 9}$ \\
\hline
\end{tabular}

Table 7. Theoretical Tolerances and Measurable Inherent Part Variation

Overall, this study suggests that the Optigo system is capable of meeting the requirements for automotive body measurement system Gage Repeatability and Reproducibility. The system is capable both in terms of its ability to pass Gage $R \& R$ criteria based on typical tolerance widths and in separating measurement system variation from part variation for historical levels of standard deviation.

\subsection{Optigo Vs. CMM: Feature Correlation and Accuracy}

Another potential source of measurement system error is accuracy. Traditionally, we measure the accuracy of a gage using a master part or artifact. For purposes of this study, we considered CMM measurements as the master and examined if any systematic mean biases existed between systems. We evaluated mean differences between the systems using an overall feature correlation study and a test of mean differences between measurement readings for individual discrete points.

For this analysis, we examined a more complex hood inner panel. Table 8 summarizes the correlation between features, and the average $/ 95^{\text {th }}$ percentile mean differences across common features on the hood inner panel (i.e., mean of dimension using CMM versus mean of same dimension using Optigo). Originally, we observed a correlation difference with respect to hole measurement position. However, it was determined that the method used to calculate hole 
positions was inconsistent between systems. This inconsistency was corrected and the final results are shown below. We mention this inconsistency because numerous methods exist to measure true position of holes and it is important to use common approaches to correlate the two systems.

Table 8 indicates a very strong correlation between specific discrete point measurement locations on the CMM versus the Optigo. In addition to these strong correlation values, the magnitude of the difference in means is quite small. For hole and surface measurements, the average mean deviation between systems was approximately $0.03 \mathrm{~mm}$. This finding is significantly better than typically observed in comparing measurement systems such as traditional check fixtures with EDC bushings versus CMM or in-line vision systems versus CMM.

\begin{tabular}{|l|c|c|c|c|}
\hline Group & $\begin{array}{c}\text { \# Meas } \\
\text { Pairs }\end{array}$ & $\begin{array}{c}\text { Feature } \\
\text { Correlation }\end{array}$ & $\begin{array}{c}\text { Average } \\
\text { Difference } \\
\text { CMM-Optigo }\end{array}$ & $\begin{array}{c}\text { 95th } \\
\text { Percentile } \\
\text { Difference }\end{array}$ \\
\hline Holes & 20 & 0.997 & 0.03 & 0.09 \\
\hline Edge Points & 8 & 0.996 & 0.12 & 0.22 \\
\hline Surfaces & 16 & 0.999 & 0.03 & 0.08 \\
\hline
\end{tabular}

Table 8. Reinforcement Panel Correlation/ Mean Bias Measurement Differences

Although the results are positive, some issues exist in comparing means between pairs of measurements (e.g., panel 1 with CMM vs. panel 1 with Optigo). In particular, edge points tended to have greater mean differences than holes and surfaces. Figures 12 and 13 provide box plots showing observed differences in correlation and mean difference magnitude by feature type categories (holes, edge points, surfaces). Interestingly, the edge points for the Optigo system are biased to one side whereas the hole positions and surface measurements are scattered about a difference of 0 . Since the mean difference shown in these figures is calculated using CMMOptigo measurements, the positive values suggest that the CMM trim edge measurement readings are more outboard.

An explanation for this phenomenon relates to where on the part these edge points are measured. The CMM uses a probe with a wider contact area. Thus, the CMM values typically pick up the maximum tangent point of the sheet metal edge. In contrast, the Optigo system 
measures along the top of the surface. Body panel edge points are created by trim operations in the stamping die lineup. So, as the die trim steels wear, the breakage at the top of a surface will be different from the breakage in the middle of the blank. As a result, we would expect edge points to be slightly biased when compared to CMM measurements. However, given that trim edge feature requirements typically have wider tolerances $( \pm 0.7$ to \pm 1.5$)$ compared with mating surfaces or hole positions, this difference would not likely have a practical impact on the final body assembly process.

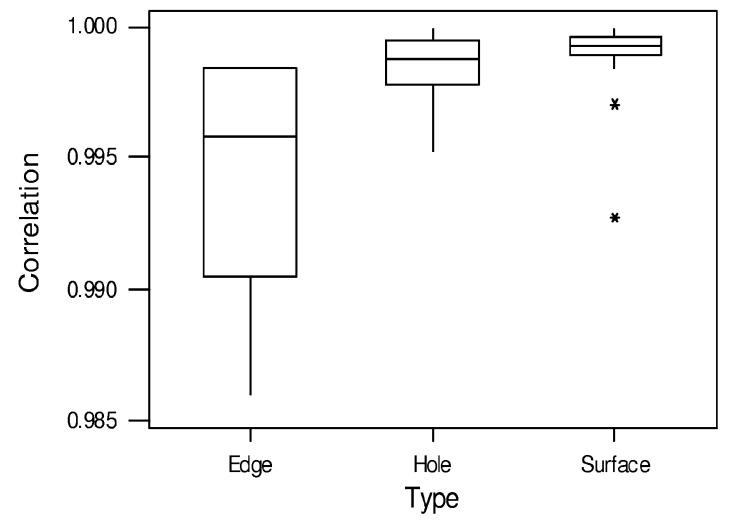

Figure 12. Correlation Differences for Each Set of Panel Measurement by Type

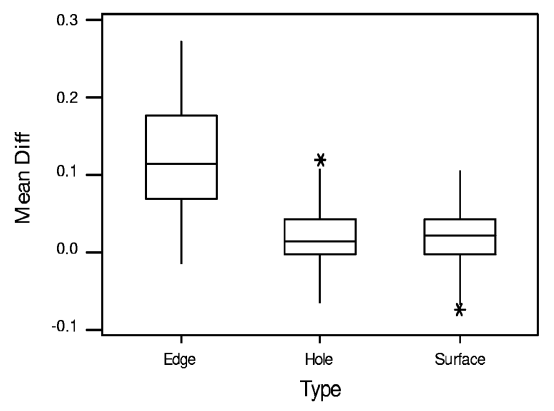

Figure 13. Mean Differences for Each Set of Panel Measurement by Feature Type

These measurement system correlation findings are particularly critical because a primary reason for point cloud data is to better represent larger, more complex automotive body parts. Compared with measurement system Gage $R \& R$, having the ability to effectively replicate CMM measurement values in terms of correlation and mean bias for discrete locations is probably more 
important in terms of diagnostic value. In addition, the Optigo system provides full point cloud data to better evaluate conformance of complex panel shapes to design nominal dimensions.

\section{Conclusions}

Historically, automotive body measurements have relied on discrete point checking systems to produce inspection data. The limitations of these systems are well known. They tend to require significant engineering resources to establish key part features, and often the selected features are in the wrong location or are insufficient to effectively diagnose next-level assembly process build problems. A technology that has the potential to provide significantly better diagnostic capability is 3D non-contact measurement systems, which produce point cloud data.

However, for these systems to represent a viable alternative, they must be able to meet industry expectations for Gage R\&R and accuracy. The various case studies used in this report demonstrate that the Optigo system is capable of meeting these industry expectations and is very similar to the CMM in terms of accuracy as supported by high measurement system correlation.

These case studies, however, do indicate that some inherent differences exist that could potentially affect adoption of 3D non-contact measurement systems. Among the potential concerns is higher static repeatability in the Optigo system. In addition, some minor differences in measurement may result due to the difference between using a physical touch probe versus a non-contact system. Still, the significant added benefits of the Optigo system in terms of its ability to provide more comprehensive panel shape representation likely outweighs these particular measurement system differences.

To further assess the "productionization" of 3D non-contact measurement systems, additional comparisons are needed in terms of system costs, benefits, and actual applications. Having point cloud data available for problem diagnostics is only one part of the equation; understanding how to effectively utilize this point cloud data is another. Historically, not all stamping deviations necessarily translate into assembly problems. So, having more outspecification data potentially could lead to over-adjustment or unnecessary rework. These issues and others related to system cost comparisons will be the subject of future reports.

In conclusion, these case studies indicate that the Optigo 200 system is capable of meeting industry standards for measurement system capability. More importantly, these results suggest that manufacturers may enhance their measurement system effectiveness in terms of diagnostic capability and total system costs using 3D non-contact measurement. 


\section{REFERENCES}

1. Gershon R. and Benady M., "Noncontact 3-D Measurement Technology Enters a New Era," Quality Digest, 2000.

2. Mitchell, G., "Use Sensors Intelligently," Controls Engineering Online, 2001.

3. Measurement Systems Analysis. Reference Manual. $3^{\text {rd }}$ Edition. Automotive Industry Action Group, 2002.

4. Liggett, J.V., Dimensional Variation Management Handbook - A Guide for Quality, Design, and Manufacturing Engineers. Englewood Cliffs, NJ: Prentice Hall. 1993.

5. Hammett, P. and Baron, J., Automotive Body Measurement System Capability. Report prepared for the Auto Steel Partnership Program. 1999. 